\title{
The effect of claw horn disruption lesions and body condition score at dry-off on survivability, reproductive performance, and milk production in the subsequent lactation
}

\author{
V. S. Machado, L. S. Caixeta, J. A. A. McArt, and R. C. Bicalho ${ }^{1}$ \\ Department of Population Medicine and Diagnostic Sciences, College of Veterinary Medicine, Cornell University, Ithaca, NY 14853
}

\begin{abstract}
The objective of this study was to evaluate the effects of claw horn disruption lesions (CHDL; sole ulcers and white line disease) and body condition score (BCS) at dry-off on survivability, milk production, and reproductive performance during the subsequent lactation. An observational prospective cohort study was conducted on a large commercial dairy in Cayuga County, New York, from September 2008 until January 2009. A total of 573 cows enrolled at dry-off were scored for body condition and hoof trimmed; digits were visually inspected for the presence of CHDL. The BCS data were recategorized into a 3-level variable BCS group (BCSG), with cows with BCS $<3$ placed in BCSG $1(\mathrm{n}=113)$, cows with BCS $=3$ placed in BCSG $2(\mathrm{n}=254)$, and cows with BCS $>3$ placed in BCSG $3(\mathrm{n}=206)$. Cows in BCSG 2 were 1.35 and 1.02 times more likely to conceive than cows in BCSG 1 and 3, respectively. The cull/death hazard for BCSG 1 cows was 1.55 and 1.47 times higher than for cows in BCSG 2 and BCSG 3, respectively. Milk yield for cows in BCSG $2(44.6 \mathrm{~kg} / \mathrm{d}$, 95\% CI 43.4-45.8) was significantly greater than that for cows in BCSG 1 (41.5 kg/d, 95\% CI 39.8-43.3). Cows with previous lactation days open $\leq 91$ had 1.6 times higher odds of being classified into BCSG 1 at dry-off; cows with previous lactation mature-equivalent 305-d milk >14,054 kg had a similar 1.6 times higher odds of being classified into BCSG 1. Claw horn disruption lesions were found in $24.4 \%$ of the cows $(n=140)$ at dry-off. Cows without CHDL were 1.4 times more likely to conceive than cows with CHDL. Additionally, lesion cows were 1.7 times more likely to die or be culled than nonlesion cows. Absence of CHDL did not have a significant effect on milk yield. These findings highlight the importance of claw health and BCS at the end of lactation on future survival and performance.

Key words: animal welfare, body condition score, dairy cow, lameness
\end{abstract}

Received February 17, 2010.

Accepted June 3, 2010.

${ }^{1}$ Corresponding author: rcb28@cornell.edu

\section{INTRODUCTION}

Animal welfare is a growing concern in the dairy industry; both public opinion and farm economics are driving forces in improving the well-being of dairy cows. In North America, lameness is the most important cause of disruption in bovine welfare (Vermunt, 2007); it also has a negative association with milk production and reproductive performance and leads to increased risk of culling or death (Rajala-Schultz and Gröhn, 1999a; Warnick et al., 2001; Bicalho et al., 2008).

Similar to lameness, poor body condition has economic and welfare implications (Roche et al., 2009). Over- or underconditioned cows produce less milk and have inferior reproductive performance compared with their "normally" conditioned counterparts (Waltner et al., 1993; Domecq et al., 1997a; Hoedemaker et al., 2009). Additionally, low BCS has been repeatedly associated with lameness (Gearhart et al., 1990; Hassall et al., 1993; Hoedemaker et al., 2009). Previous research by our group has shown that there is a significant association between under conditioned cows and the size of their digital cushions, and that cows with thinner digital cushions were at a significantly higher risk of being diagnosed with claw horn disruption lesions (CHDL) including sole ulcers and white line disease (Bicalho et al., 2009).

The objective of this study was to evaluate the effects of CHDL and BCS at dry-off on survivability, milk production, and reproductive performance during the subsequent lactation. Our research hypothesis was that the presence of CHDL and low BCS at dry-off would have a negative effect on future milk yield and reproductive performance and increase the risk of culling or death.

\section{MATERIALS AND METHODS}

\section{Farm and Management}

Data were collected from a dairy farm located in Cayuga County, New York; cows were enrolled into the study from September 11, 2008, until January 5, 
2009, and were followed up until September 15, 2009. This period was chosen to meet the sample size criteria that we assumed that would be enough to conduct the study. This farm was selected because of its long-standing relationship with the Ambulatory and Production Medicine Clinic at Cornell University (Ithaca, NY). The farm milked 2,800 Holstein cows 3 times daily in a double 52-stall parallel milking parlor. Lactating cows were housed in free-stall barns with concrete stalls covered with mattresses and bedded with recycled manure solids. The pen alleys had grooved-concrete flooring and were cleaned by automatic scrapers; all walkways to and from the milking barn and holding pen were covered with rubber. Dry cows were housed in free-stall barns with concrete stalls and bedded with sand, and the average length of dry period was $45 \mathrm{~d}(\mathrm{SD}=10)$. The pen alleys had grooved-concrete flooring and were tractor scraped once per day.

Lactating cows were fed a TMR consisting of approximately $55 \%$ forage (corn silage, haylage, alfalfa hay, and wheat straw) and $45 \%$ concentrate (cornmeal, soybean meal, canola, cottonseed, and citrus pulp). The diet was formulated to meet or exceed the NRC (2001) nutrient requirements for lactating Holstein cows weighing $650 \mathrm{~kg}$ and producing $45 \mathrm{~kg}$ of $3.5 \% \mathrm{FCM}$.

All lactating cows were scheduled to receive routine hoof trimming twice yearly. A protocol created in DairyComp 305 (Valley Ag Software, Tulare, CA) prompted trimming for lactating cows $150 \mathrm{~d}$ after the previous routine hoof trimming. Furthermore, all cows received routine hoof trimming at dry off. Trained farm employees observed cows walking into the milking parlor and recorded the number of visually lame cows; lame cows were trimmed by farm employees daily.

The reproductive management utilized a combination of Presynch (Moreira et al., 2001), Ovsynch (Pursley et al., 1995), Resynch (Fricke et al., 2003), and detection of estrus, with 25 to $30 \%$ of cows bred via timed AI and the remainder bred after detection of estrus solely by activity monitors (Alpro, DeLaval, Kansas City, MO).

\section{Study Design and Data Collection}

A prospective cohort study design was used. The data were collected at dry-off by one of 3 trained and experienced veterinarians. Cows were scored for body condition at dry-off using a 5-point scale with a quarterpoint system as described by Edmonson et al. (1989), at which time they underwent routine hoof trimming using the functional hoof trimming method as described by Toussaint Raven et al. (1985). Hoof trimming was performed with a standing hoof trimming chute HSeries (Comfort Hoof Care, Baraboo, WI), and digits were visually inspected for the presence of CHDL. Hoof trimming and collection of data on BCS and presence of CHDL were completed by 1 of 3 veterinarians who were trained by the principal investigator. Whenever digital lesions were diagnosed, appropriate therapy was completed following existing farm protocols, which were developed by the farm veterinarians. Data regarding survivability, reproductive performance, and milk yield during the subsequent lactation were extracted from the farm's DairyComp 305 database.

\section{Statistical Analysis}

To facilitate data analysis and interpretation, the variables BCS group (BCSG), CHDL, previous lactation days open (PDOPN), and previous lactation mature-equivalent 305-d milk (PME305) were created. The BCS groups were categorized as follows: BCSG = 1 if $\mathrm{BCS}<3, \mathrm{BCSG}=2$ if $\mathrm{BCS}=3$, and $\mathrm{BCSG}=3$ if BCS $>3$. Lactation groups were defined for the subsequent lactation and were dichotomized into lactation $=$ 2 and lactation $>2$. The variable CHDL was defined as follows: $\mathrm{CHDL}=1$ if the cow was detected with a sole ulcer, white line disease, or both; CHDL $=0$ if the cow did not have a sole ulcer or white line disease on inspection. Sole ulcer was defined as a circumscribed area of fresh tissue or exposed granulation tissue in the sole; white line disease was defined as areas of hemorrhage and necrosis of the corium in the white line region of the sole (Toussaint Raven et al., 1985). The variables PDOPN and PME305 were dichotomized using a cutoff value suggested by receiver operating characteristic curve analysis, which was performed using MedCalc version 9.2.0.1 (MedCalc Software, Mariakerke, Belgium). Additionally, descriptive statistics were performed using the Freq and Univariate procedures of SAS (SAS Institute Inc., Cary, NC).

The effects of CHDL and BCSG on reproduction and survival were analyzed by Cox's proportional hazard model using the proportional hazard regression procedure in SAS; risk period was defined as time from calving to event (conception or death/culling) or censoring. For analysis of reproduction, cows were right-censored if not diagnosed pregnant before culling, death, or the end of the data collection period. For analysis of survival, cows were censored if they were alive at the end of the data collection period. Variables offered to the models included CHDL or BCSG and cow age in days. Two-way interactions between CHDL or BCSG and parity were tested. To illustrate the effect of CHDL and BCSG on reproduction and survivability, KaplanMeier survival analysis was performed using Medcalc version 10.4.0.0; the Logrank test was used to compute $P$-values. 
Table 1. Descriptive statistics of 573 cows at study enrollment by lactation and BCS group (BCSG) ${ }^{1}$ including the number of cows per group and presence of claw horn disruption lesions (CHDL) at dry-off

\begin{tabular}{lrc}
\hline Group & Cows, $\mathrm{n}$ & Incidence of CHDL, \% \\
\hline Lactation 2 & & \\
BCSG 1 & 40 & 22.5 \\
BCSG 2 & 157 & 8.9 \\
BCSG 3 & 87 & 6.9 \\
Total & 284 & 10.2 \\
Lactation 3 & & \\
BCSG 1 & 34 & 47.1 \\
BCSG 2 & 64 & 28.1 \\
BCSG 3 & 58 & 17.2 \\
Total & 156 & 28.2 \\
Lactation $\geq 4$ & & \\
BCSG 1 & 39 & 69.2 \\
BCSG 2 & 33 & 57.6 \\
BCSG 3 & 61 & 34.4 \\
Total & 133 & 50.4 \\
All lactations & & \\
BCSG 1 & 113 & 46.0 \\
BCSG 2 & 254 & 20.1 \\
BCSG 3 & 206 & 18.0 \\
\hline
\end{tabular}

${ }^{1} \mathrm{BCSG} 1: \mathrm{BCS}<3$, BCSG 2: $\mathrm{BCS}=3$, and BCSG 3 : $\mathrm{BCS}>3$.

To assess the effect of BCSG and CHDL on milk yield, 2 repeated-measures ANOVA were performed using the MIXED procedure of SAS. The following independent variables were offered to the model: BCSG or CHDL, milk test number ( 1 to 6 ), and parity. The monthly milk weights were longitudinally collected (repeated measures); the error term was modeled by imposing a first-order autoregressive covariance structure to account appropriately for the within-cow correlation of milk measurements. The outcome variable was ex-

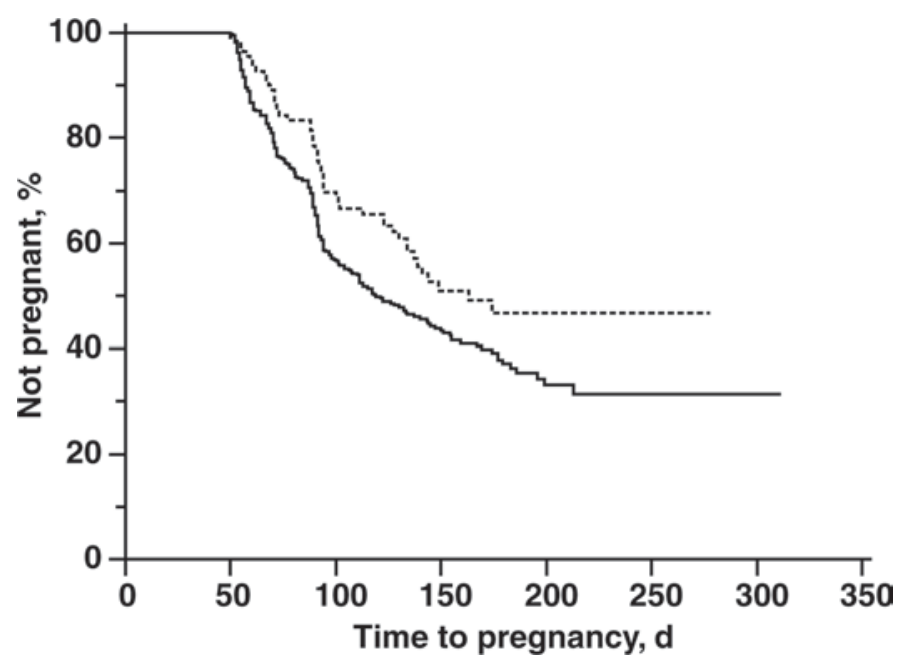

Figure 1. Kaplan-Meier survival analysis of calving-to-conception interval for cows diagnosed with claw horn disruption lesions (CHDL) at dry-off. Cows diagnosed with CHDL (dotted line) had a median calving-to-conception interval of $163 \mathrm{~d}$ compared with $119 \mathrm{~d}$ for nonlesion cows (solid line). amined for normality by visual inspection of frequency histograms.

A logistic model was fitted in SAS using the Logistic procedure to examine in detail the effect of the dichotomized PDOPN and PME305 on the odds of low BCS at dry off. The outcome variable was the dichotomized BCS where cows with BCS $<3$ were classified as 1 and the cows with $\mathrm{BCS} \geq 3$ were classified as 0 . A descending response level of ordering was used to model the odds of a BCS $<3$ event. The independent variables offered to the model were dichotomized PDOPN, PME305, and parity. Biologically plausible 2-way interactions were tested.

For all models described above, independent variables and their respective interactions were kept when $P<$ 0.10 in an attempt to reduce the type II error risk while maintaining a stringent type I error risk of $5 \%$.

\section{RESULTS}

\section{Descriptive Statistics}

A total of 573 cows were enrolled in the study; descriptive statistics concerning lactation, BCSG, and presence of CHDL at dry-off can be seen in Table 1 . Additionally, no cows were lost to follow up during the dry period.

\section{Effect of CHDL and BCS on Reproduction}

The median calving-to-conception interval was $119 \mathrm{~d}$ for nonlesion cows and $163 \mathrm{~d}$ for the cows with CHDL (Logrank test, $P=0.02$ ). By 200 DIM, the percentage of cows pregnant was significantly lower for cows with CHDL at dry off: 50 and $70 \%$ of cows with and without CHDL at dry-off, respectively (Figure 1). Additionally, a multivariable Cox's proportional hazard model was performed and the only variables retained in this model were age in days and the variable CHDL; nonlesion cows were 1.4 times more likely to conceive when compared with cows diagnosed with a CHDL at dry-off (hazard ratio $=1.4, P=0.02$ ).

By 200 DIM, $70 \%$ of cows in BCSG $=2$ and BCSG $=3$ were pregnant, and only $45 \%$ of cows in BCSG $=$ 1 were pregnant (Figure 2). The multivariable Cox's proportional hazard model indicated that cows in the $\mathrm{BCSG}=2$ were 1.35 and 1.02 times more likely to conceive than cows in BCSG 1 and 3 , respectively $(P$ $=0.04)$.

\section{Effect of CHDL and BCS on Survival}

Cox's proportional hazards analysis showed that the hazard of death or culling was significantly greater in 


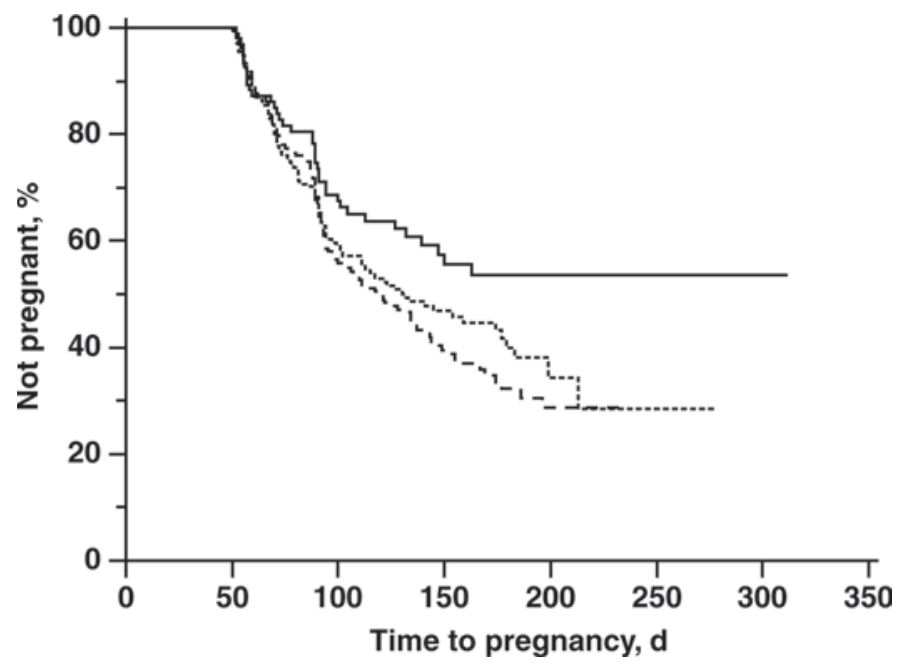

Figure 2. Kaplan-Meier survival analysis of calving-to-conception interval by body condition score group (BCSG) at dry-off. The median calving-to-conception intervals for BCSG 2 (dotted line) and BCSG 3 (dashed line) were 119 and $132 \mathrm{~d}$, respectively. The median calving-toconception interval for BCSG 1 (solid line) was not estimated because by the end of the follow-up period, more than $50 \%$ of those cows were not pregnant cows; the effect of BCSG was significant $(P$-value $=$ $0.02)$.

cows with CHDL at dry-off, with CHDL cows 1.7 times more likely to die or be culled compared with cows without CHDL at dry-off $(P<0.01)$. Kaplan-Meier survival analysis showed that the median time until death or culling for cows with CHDL was significantly

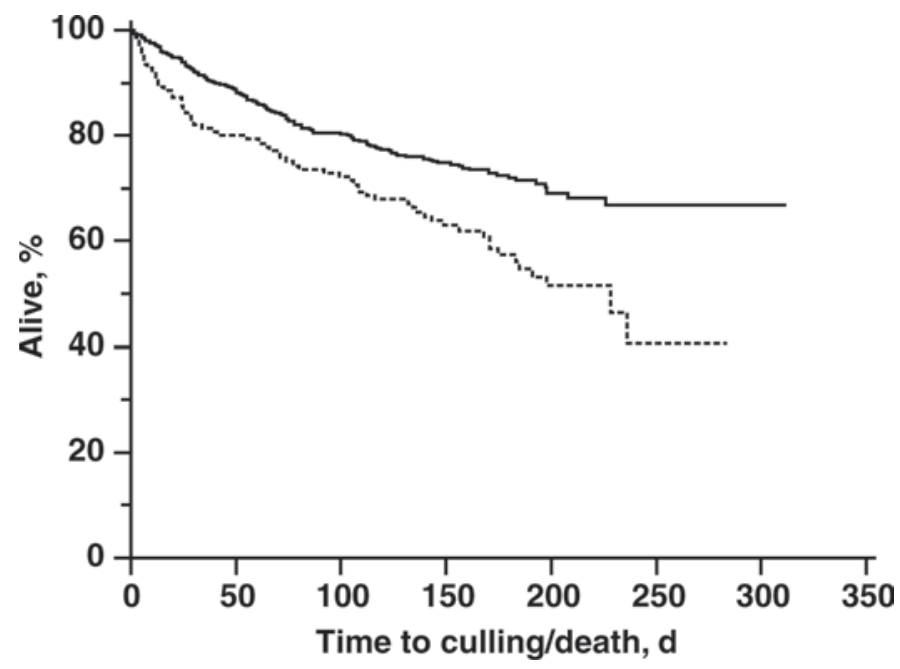

Figure 3. Kaplan-Meier survival analysis of probability of death or culling for cows diagnosed with $(\mathrm{n}=140)$ or without $(\mathrm{n}=433)$ claw horn disruption lesions (CHDL). Median time until death or culling for cows with CDHL (dotted line) was 228 and was significantly greater than in those without CHDL $(P<0.01)$. Median interval from calving to culling or death was not estimated for the group of nonlesion cows (solid line) because over $65 \%$ of the cows in that group were still alive by the end of the follow-up period.

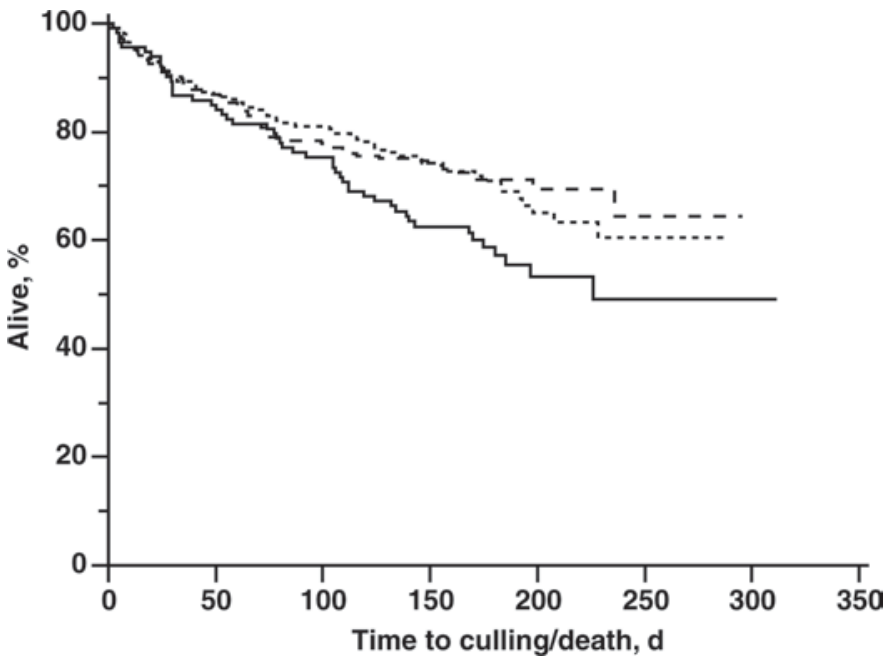

Figure 4. Kaplan-Meier survival analysis of probability of death or culling by body condition score group (BCSG) at dry-off. Median time until culling or death for the BCSG 1 (solid line) was $226 \mathrm{~d}$ and was significantly different $(P=0.04)$ from BCSG 2 (dashed line) or BCSG 3 (dotted line).

greater than those without CHDL (Figure 3). At 250 DIM, $70 \%$ of the nonlesion cows remained in the herd whereas only $40 \%$ of the cows with CHDL at dry-off were still in the herd.

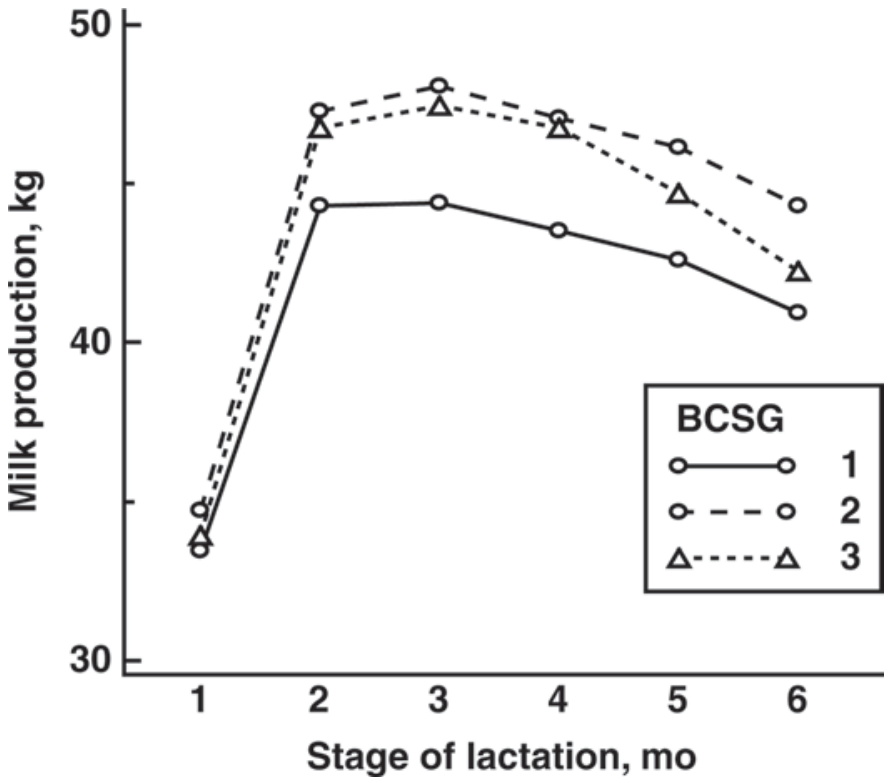

Figure 5. Lactation curve showing milk production $(\mathrm{kg})$ by month of lactation, and by BCS group (BCSG) at dry-off, with BCSG 1 cows having BCS $<3(\mathrm{n}=113)$, BCSG 2 cows having BCS $=3(\mathrm{n}=254)$, and BCSG 3 cows having BCS $>3(n=206)$. Variables used in the model include milk production, stage of lactation, lactation number, and BCSG at dry-off. The least squares means milk production for BCSG 1,2 , and 3 were $41.5,44.6$, and $43.6 \mathrm{~kg}$, respectively ( $P$-value $=0.02)$. 
Table 2. Least squares means (LSM) of daily milk yield for categorical fixed effects used in the model (lactation number and month of lactation) based on BCS group (BCSG) at dry-off with BCSG 1 cows having $\mathrm{BCS}<3(\mathrm{n}=113)$, BCSG 2 cows having $\mathrm{BCS}=3(\mathrm{n}=254)$, and BCSG 3 cows having BCS $>3(\mathrm{n}=206)$

\begin{tabular}{lccc}
\hline Variable & LSM $(\mathrm{kg} / \mathrm{d})$ & $95 \% \mathrm{CI}$ & $P$-value \\
\hline BCSG & & & \\
1 & 41.5 & $39.8-43.3$ & 0.02 \\
2 & 44.6 & $43.4-45.8$ & \\
3 & 43.6 & $42.4-44.9$ & \\
Lactation & & & \\
2 & 44.3 & $43.2-45.5$ & $<0.01$ \\
$\geq 3$ & 42.2 & $41.1-43.3$ & \\
Month & & & \\
1 & 34.1 & $33.1-35.0$ & $<0.01$ \\
2 & 46.1 & $45.1-47.1$ & \\
3 & 46.6 & $45.6-47.6$ & \\
4 & 45.8 & $44.7-46.8$ & \\
5 & 44.5 & $43.3-45.6$ & \\
6 & 42.5 & $41.1-43.9$ & \\
\hline
\end{tabular}

Cox's proportional hazards analysis of BCSG showed that the hazard of death or culling was significantly greater in BCSG 1 cows, with those cows 1.55 and 1.47 times more likely to die or be culled than cows in BCSG 2 or BCSG 3 , respectively $(P<0.01)$. Kaplan-Meier survival analysis showed that the median time until death or culling for cows in BCSG 1 was significantly greater than those in BCSG 2 or BCSG 3 (Figure 4). At 250 DIM, approximately $45 \%$ of cows in BCSG 1, $60 \%$ of cows in BCSG 2 , and $65 \%$ of cows in BCSG 3 remained in the herd.

\section{Effect of CHDL and BCS on Milk Yield}

Least squares means for average daily milk yield based on BCSG was calculated by group as well as for the categorical fixed effects used in the model, lactation and stage of lactation (Table 2). Milk yield differed

Table 3. Least squares means (LSM) of daily milk yield for categorical fixed effects used in the model (lactation number and month of lactation) based on presence $(\mathrm{n}=140)$ or absence $(\mathrm{n}=433)$ of claw horn disruption lesions (CHDL) at dry-off

\begin{tabular}{lccc}
\hline Variable & LSM $(\mathrm{kg} / \mathrm{d})$ & $95 \% \mathrm{CI}$ & $P$-value \\
\hline CHDL & & & \\
Present & 43.5 & $42.6-44.4$ & 0.58 \\
$\quad$ Absent & 44.1 & $42.4-45.8$ & \\
Lactation & & & \\
2 & 45.1 & $43.8-46.4$ & $<0.01$ \\
$\geq 3$ & 42.5 & $41.4-43.6$ & \\
Month & & & \\
1 & 34.2 & $33.1-35.3$ & $<0.01$ \\
2 & 46.7 & $45.5-47.8$ & \\
3 & 47.3 & $46.2-48.5$ & \\
4 & 46.6 & $45.4-47.8$ & \\
5 & 45.0 & $43.7-46.3$ & \\
6 & 43.1 & $41.5-44.6$ & \\
\hline
\end{tabular}

significantly based on BCSG as well as for the effects lactation and time, with BCSG 1, BCSG 2, and BCSG 3 cows producing an average of 41.5, 44.6, and 43.6 $\mathrm{kg} / \mathrm{d}$, respectively $(P=0.02)$. Average daily milk yield in BCSG 1 cows was significantly lower than in BCSG 2 and BCSG 3 cows (Figure 5).

Least squares means for average daily milk yield was also calculated based on presence of CHDL at dry-off as well as for categorical fixed effects used in the model (Table 3). Cows diagnosed with CHDL at dry-off had a similar average daily milk yield compared with cows without CHDL at dry-off at 43.5 and $44.1 \mathrm{~kg} / \mathrm{d}$, respectively $(P=0.58$, Table 2$)$.

\section{Logistic Regression Model}

A multivariable logistic regression was performed to assess the effect of PDOPN, lactation, and PME305 on the odds of low BCS (BCS <3) at dry off. A total of 237 cows ( $41 \%$ of enrolled cows) had PDOPN $\leq 91$ d; 278 cows (49\% of enrolled cows) had a PME305 $>14,054 \mathrm{~kg} / 305 \mathrm{~d}$. Cows with PDOPN $\leq 91$ had a 1.6 times higher odds of being classified into the group of underconditioned cows (BCS <3) at dry-off. Additionally, cows with PME305 >14,054 were also at 1.6 times increased odds of being underconditioned at dry-off. Cows in lactation $\geq 4$ had 2.8 times higher odds and cows in lactation 3 had 1.7 times higher odds of being classified as underconditioned $(\mathrm{BCS}<3)$ than cows in lactation 2 (Table 4).

\section{DISCUSSION}

This study evaluated the effects of CHDL (sole ulcers and white line disease) and BCS at dry-off on survivability, milk production, and reproductive performance during the subsequent lactation. The results indicated that BCSG and CHDL at dry-off were significantly associated with reproductive performance and survivability during the subsequent lactation. Additionally,

Table 4. Logistic regression model showing the effect of previous lactation days open (PDOPN), lactation number, and previous lactation mature-equivalent 305-d milk (PME305) on the odds of low BCS $(\mathrm{BCS}<3)$ at dry-off

\begin{tabular}{lcc}
\hline Variable & $\begin{array}{c}\text { Adjusted } \\
\text { odds ratio }\end{array}$ & $P$-value \\
\hline PDOPN $>91$ & Baseline & 0.04 \\
PDOPN $\leq 91$ & 1.6 & \\
Lactation $=2$ & Baseline & $<0.001$ \\
Lactation $=3$ & 1.7 & \\
Lactation $\geq 4$ & 2.8 & 0.03 \\
PME305 $\leq 14,054$ & Baseline & \\
PME305 $>14,054$ & 1.6 & \\
\hline
\end{tabular}


BCSG was significantly associated with milk production in the subsequent lactation, with underconditioned cows $(\mathrm{BCS}<3)$ producing an average of $3.1 \mathrm{~kg} / \mathrm{d}$ less milk than cows with $\mathrm{BCS}=3$.

Multiple studies have found similar associations of BCS and future milk production. Roche et al. (2007) found that BCS at calving, BCS nadir, and BCS loss from calving to nadir had significant effects on milk production, and additional studies have reported that BCS at calving was significantly associated with milk yield (Waltner et al., 1993; Berry et al., 2007). Domecq et al. (1997b) reported that a 1-point increase in BCS between dry-off and parturition was associated with an additional $545.5 \mathrm{~kg}$ of milk in the first $120 \mathrm{~d}$ of lactation. However, a study conducted by Pedron et al. (1993) found no association between BCS at calving and subsequent milk production. The present study differs from the published literature concerning the time of body condition scoring; data in this study were collected at dry-off, whereas many previous studies have assessed BCS at parturition or during early lactation (Pedron et al., 1993; Berry et al., 2007; Roche et al., 2007).

The biological justification for the effect of BCS on performance during the subsequent lactation can be explained by the negative energy balance period experienced by cows from parturition until 40 to 100 DIM (Coffey et al., 2002; Roche et al., 2007). Because of negative energy balance after calving and changes in body reserves, underconditioned cows have fewer energy resources that can be mobilized for milk production. However, underconditioned cows are at increased risk of several health conditions known to affect milk production such as lameness and retained placenta (Hoedemaker et al., 2009). In addition, underconditioned cows $(\mathrm{BCS}<3)$ were less likely to conceive than their better conditioned counterparts (BCS $\geq 3$ ). Cows in negative energy balance divert energy from reproduction resulting in prolonged postpartum anestrus and poorer reproductive performance (Chagas et al., 2007; Peter et al., 2009). Domecq et al. (1997a) reported that cows with BCS loss during the first month of lactation were less likely to conceive than cows that did not lose BCS. Hoedemaker et al. (2009) reported that cows with BCS $<3$ at calving had a higher risk of dystocia and retained placenta, and cows with BCS $<3$ during early lactation were at a higher risk of developing endometritis and a lower risk of becoming pregnant compared with cows with $\mathrm{BCS} \geq 3$. Hence, the compromised reproductive performance observed in underconditioned cows.

Data from this study showed that underconditioned cows (BCSG 1) were at an increased risk of death or cull than cows in BCSG 2 or BCSG 3. The relationship between low BCS and decreased reproductive performance may explain the negative effect of BCS on culling, because poor reproductive performance is associated with increased culling (Rajala-Schultz and Gröhn, 1999a). Additionally, as shown in this study, thinner cows tend to produce less milk, which can influence survivability because milk yield has a significant effect on culling decisions (Rajala-Schultz and Gröhn, 1999b). Another explanation for the relationship between low BCS and increased culling relates low BCS to lameness. Bicalho et al. (2009) reported that BCS was positively associated with digital cushion thickness, and that thinner digital cushions associated in higher prevalence of sole ulcers and white line disease. In this study, cows with CHDL at dry-off were more likely to be culled than cows diagnosed without CHDL, and presumably cows with low BCS had a thin digital cushion and were at increased risk of having a CHDL and therefore culling. In the present study, cows affected with CHDL at dry-off received appropriate therapeutic hoof trimming immediately after the diagnosis. Consequently, it is possible that the negative effects of CHDL and BCSG encountered in this study are conservative estimates because the lame cows received appropriate therapy immediately after CHDL diagnosis at dry-off. From this study, a BCS of 3 at dry-off optimized subsequent lactation milk yield, reproductive performance, and longevity.

Cows affected with CHDL at dry off were less likely to conceive and more likely to die or be culled compared with cows with no CHDL at dry-off. The effect of lameness on reproductive performance and survivability has been extensively reported in the literature (Rajala-Schultz et al., 1999; Warnick et al., 2001). Furthermore, the effect of CHDL on subsequent lactation milk production was not significant. Several studies have attempted to estimate the effect of lameness on milk production and the published literature presents conflicting results. Hernandez et al. (2002) reported a nonsignificant difference in milk production, with lame cows producing less milk compared with their nonlame counterparts. Sogstad et al. (2007) did not find an association between lameness and milk production but reported an increase in milk yield in cows after hoof trimming. Other studies have found a significant negative effect of lameness on milk yield (Rajala-Schultz et al., 1999; Warnick et al., 2001; Bicalho et al., 2008). In the present study, CHDL was evaluated at dry off in contrast from others (Rajala-Schultz et al., 1999; Warnick et al., 2001; Bicalho et al., 2008) who evaluated the effect of lameness events throughout the lactation on milk production.

This study also found a positive relationship between PDOPN and BCS at dry-off and a negative association between PME305 and BCS at dry-off. As consequence 
of negative energy balance, cows typically lose body condition from parturition up until 60 DIM and once the negative energy balance is resolved (40-100 DIM), cows will gradually recover BCS until the end of lactation (Coffey et al., 2002; Chagas et al., 2007; Roche et al., 2007). Thus, it is logical to conclude that cows conceiving earlier in lactation $(\mathrm{PDOPN} \leq 91)$ had less time to recover BCS, because the time from cessation of negative energy balance until the end of lactation would be significantly shorter compared with cows that conceived later in lactation (PDOPN >91). The economic consequences of strategically extending the lactation of high-producing cows have been evaluated previously (Arbel et al., 2001). The results of the present study suggest that extending the lactations of certain high-producing cows by extending the voluntary waiting period could lead to higher median BCS at dry off and potentially improve health and production in the subsequent lactation.

\section{CONCLUSIONS}

Cows diagnosed with CHDL at dry-off were more likely to die or be culled and less likely to become pregnant in the next lactation than cows without CHDL. Cows underconditioned (BCSG $=1$ ) at dry-off were more likely to be culled, produced less milk, and had inferior reproductive performance in the subsequent lactation compared with their better conditioned herdmates (BCSG > 1). Additionally, cows scored as overconditioned at dry-off (BCSG $=3$ ) consistently underperformed compared with cows with $\mathrm{BCS}=3$ at dryoff, which was considered an optimal body condition in this study. Moreover, cows that had PDOPN $\leq 91$ and cows with PME305 >14,054 kg were more likely to be classified into the group of underconditioned $(\mathrm{BCS}<3$ ) cows at dry-off. Further studies are needed to evaluate strategies to mitigate the prevalence, incidence, and consequences of underconditioned and lame cows.

\section{REFERENCES}

Arbel, R., Y. Bigun, E. Ezra, H. Sturman, and D. Hojman. 2001. The effect of extended calving intervals in high-yielding lactating cows on milk production and profitability. J. Dairy Sci. 84:600-608.

Berry, D. P., F. Buckley, and P. Dillon. 2007. Body condition score and live-weight effects on milk production in Irish Holstein-Friesian dairy cows. Animal 1:1351-1359.

Bicalho, R. C., V. S. Machado, and L. S. Caixeta. 2009. Lameness in dairy cattle: A debilitating disease or a disease of debilitated cattle? A cross-sectional study of lameness prevalence and thickness of the digital cushion. J. Dairy Sci. 92:3175-3184.

Bicalho, R. C., L. D. Warnick, and C. L. Guard. 2008. Strategies to analyze milk losses caused by diseases with potential incidence throughout the lactation: A lameness example. J. Dairy Sci. 91:2653-2661.
Chagas, L. M., J. J. Bass, D. Blache, C. R. Burke, J. K. Kay, D. R. Lindsay, M. C. Lucy, G. B. Martin, S. Meier, F. M. Rhodes, J. R. Roche, W. W. Thatcher, and R. Webb. 2007. Invited review: New perspectives on the roles of nutrition and metabolic priorities in the subfertility of high-producing dairy cows. J. Dairy Sci. 90:4022-4032.

Coffey, M. P., G. Simm, and S. Brotherstone. 2002. Energy balance profiles for the first three lactations of dairy cows estimated using random regression. J. Dairy Sci. 85:2669-2678.

Domecq, J. J., A. L. Skidmore, J. W. Lloyd, and J. B. Kaneene. 1997a. Relationship between body condition scores and conception at first artificial insemination in a large dairy herd of high yielding Holstein cows. J. Dairy Sci. 80:113-120.

Domecq, J. J., A. L. Skidmore, J. W. Lloyd, and J. B. Kaneene. 1997b. Relationship between body condition scores and milk yield in a large dairy herd of high yielding Holstein cows. J. Dairy Sci. $80: 101-112$.

Edmonson, A. J., I. J. Lean, L. D. Weaver, T. Farver, and G. Webster. 1989. A body condition scoring chart for Holstein dairy cows. J. Dairy Sci. 72:68-78.

Fricke, P. M., D. Z. Caraviello, K. A. Weigel, and M. L. Welle. 2003. Fertility of dairy cows after resynchronization of ovulation at three intervals following first timed insemination. J. Dairy Sci. 86:3941-3950.

Gearhart, M. A., C. R. Curtis, H. N. Erb, R. D. Smith, C. J. Sniffen, L. E. Chase, and M. D. Cooper. 1990. Relationship of changes in condition score to cow health in Holsteins. J. Dairy Sci. 73:31323140.

Hassall, S. A., W. R. Ward, and R. D. Murray. 1993. Effects of lameness on the behavior of cows during the summer. Vet. Rec. 132:578-580.

Hernandez, J., J. K. Shearer, and D. W. Webb. 2002. Effect of lameness on milk yield in dairy cows. J. Am. Vet. Med. Assoc. 220:640-644.

Hoedemaker, M., D. Prange, and Y. Gundelach. 2009. Body condition change ante- and postpartum, health and reproductive performance in German Holstein cows. Reprod. Domest. Anim. 44:167-173.

Moreira, F., C. Orlandi, C. A. Risco, R. Mattos, F. Lopes, and W. W. Thatcher. 2001. Effects of presynchronization and bovine somatotropin on pregnancy rates to a timed artificial insemination protocol in lactating dairy cows. J. Dairy Sci. 84:1646-1659.

NRC. 2001. Nutrient Requirements of Dairy Cattle. 7th rev. ed. Natl. Acad. Press, Washington, DC.

Pedron, O., F. Cheli, E. Senatore, D. Baroli, and R. Rizzi. 1993. Effect of body condition score at calving on performance, some blood parameters, and milk fatty acid composition in dairy cows. J. Dairy Sci. 76:2528-2535.

Peter, A. T., P. L. Vos, and D. J. Ambrose. 2009. Postpartum anestrous in dairy cattle. Theriogenology 71:1333-1342.

Pursley, J. R., M. O. Mee, and M. C. Wiltbank. 1995. Synchronization of ovulation in dairy cows using PGF2 $\alpha$ and GnRH. Theriogenology 44:915-923.

Rajala-Schultz, P. J., and Y. T. Gröhn. 1999a. Culling of dairy cows. Part II. effects of diseases and reproductive performance on culling in Finnish Ayrshire cows. Prev. Vet. Med. 41:279-294.

Rajala-Schultz, P. J., and Y. T. Gröhn. 1999b. Culling of dairy cows. Part III. effects of diseases, pregnancy status and milk yield on culling in Finnish Ayrshire cows. Prev. Vet. Med. 41:295-309.

Rajala-Schultz, P. J., Y. T. Gröhn, and C. E. McCulloch. 1999. Effects of milk fever, ketosis, and lameness on milk yield in dairy cows. J. Dairy Sci. 82:288-294.

Roche, J. R., D. P. Berry, J. M. Lee, K. A. Macdonald, and R. C. Boston. 2007. Describing the body condition score change between successive calvings: A novel strategy generalizable to diverse cohorts. J. Dairy Sci. 90:4378-4396.

Roche, J. R., N. C. Friggens, J. K. Kay, M. W. Fisher, K. J. Stafford, and D. P. Berry. 2009. Invited review: Body condition score and its association with dairy cow productivity, health, and welfare. J. Dairy Sci. 92:5769-5801. 
Sogstad, A. M., O. Osteras, T. Fjeldaas, and A. O. Refsdal. 2007. Bovine claw and limb disorders at claw trimming related to milk yield. J. Dairy Sci. 90:749-759.

Toussaint Raven, E., R. T. Haalstra, and D. J. Peterse. 1985. Cattle Footcare and Claw Trimming. Farming Press, Ipswich, Suffolk, UK.

Vermunt, J. J. 2007. One step closer to unravelling the pathophysiology of claw horn disruption: For the sake of the cows' welfare. Vet. J. $174: 219-220$
Waltner, S. S., J. P. McNamara, and J. K. Hillers. 1993. Relationships of body condition score to production variables in high producing Holstein dairy cattle. J. Dairy Sci. 76:3410-3419.

Warnick, L. D., D. Janssen, C. L. Guard, and Y. T. Gröhn. 2001. The effect of lameness on milk production in dairy cows. J. Dairy Sci. 84:1988-1997. 